\title{
Fatigue crack and evolution prediction of compacted graphite iron under thermal loading with variable amplitude
}

\author{
Sining Pan ${ }^{\mathrm{a}, \mathrm{b}, *}, \mathrm{Ru} \mathrm{Chen}^{\mathrm{b}, \mathrm{c}}$ \\ ${ }^{\text {a }}$ College of Mechanic and Electronic Engineering, Hezhou University, China \\ ${ }^{\mathrm{b}}$ Institute of Mechanics, Chinese Academy of Sciences, China \\ ${ }^{\mathrm{c}}$ School of Engineering Science, University of Chinese Academy of Sciences, China
}

\section{A R T I C L E I N F O}

\section{Keywords:}

Crack

Thermal fatigue

Variable amplitude

Evolution prediction

Compacted graphite iron

\begin{abstract}
A B S T R A C T
With the development of engine and environmental protection, thermal cracking has become one of the main failure modes of components and materials working under complex thermal conditions. The fatigue microcrack and evolution prediction model of compacted graphite iron under thermal fatigue with variable amplitude is studied in this paper, which is induced by pulsed laser. According to the different length, microcracks shorter than $0.1 \mathrm{~mm}$ and longer than $0.3 \mathrm{~mm}$ are defined as "secondary microcrack" and "main microcrack", respectively. Results show that, the secondary microcrack caused by the superimposed high-cycle thermal loading shows different behavior of initiation and propagation with the main microcrack. The propagation of secondary microcrack usually limits in a eutectic cell, because that the energy provided in the high-cycle stage is not enough to break across the eutectic boundary. However, the main microcrack can propagate across the eutectic boundary because of enough energy provided in the low-cycle stage. With consideration of both plastic strain energy density and elastic strain energy density, a modified Paris-type model is proposed based on fractal theory. The threshold $\Delta \mathrm{W}_{\text {th }}$ is introduced to evaluate the damage contribution of elastic strain energy density. The proposed model is helpful for lifetime prediction of components and materials working under thermal fatigue with variable amplitude.
\end{abstract}

\section{Introduction}

Compacted graphite iron (CGI) is applied as combustion chamber of diesel engine, due to its low cost and excellent properties at high temperature, such as high thermal conductivity, advanced mechanical performance and so on [1,2]. The operating conditions of engine are usually transient, including start-stop cycles and regular combustion cycles [3-5]. The thermal damage induced by startstop cycle belongs to low-cycle fatigue (LCF) with large temperature change $\left(\sim 400^{\circ} \mathrm{C}\right)$ and long duration $(\sim 100 \mathrm{~s})$, and that induced by regular combustion cycle belongs to high-cycle fatigue (HCF) with small temperature range $\left(\sim 40{ }^{\circ} \mathrm{C}\right)$ and short duration $(\sim 0.1 \mathrm{~s})$. Thermal cracking damage will occur under cyclic thermal loading with variable amplitude.

Former studies about thermal fatigue resistance of cast iron are mainly induced by induction heating with constant amplitude [6-9], which is usually applied periodically by. However, due to its limitations, it is hard to achieve temperature change within milliseconds. In recent years, experiment system with precise energy distribution has been proposed [10-12]. Thermal fatigue experiment of variable amplitude can be achieved by precise temporal control of laser distribution, which provides reliable

\footnotetext{
* Corresponding author at: College of Mechanic and Electronic Engineering, Hezhou University, China.

E-mail address: supereve122@163.com (S. Pan).
} 
Table 1

Chemical composition of EN-GJV-450 (wt\%).

\begin{tabular}{llllll}
\hline $\mathrm{C}$ & $\mathrm{Si}$ & $\mathrm{Mn}$ & $\mathrm{S}$ & $\mathrm{P}$ & $\mathrm{Cu}$ \\
\hline 3.27 & 2.29 & 0.40 & 0.017 & 0.028 & 0.86 \\
\hline
\end{tabular}

experimental method for studying crack initiation and propagation behavior of components and materials working under complex thermal conditions.

A fundamental problem of evolution model is to determine the damage parameter. Researches [13,14] showed that fatigue damage was caused by all cracks, especcially the thermal fatigue damage of smooth specimen, and the surface microcracks showed collective behavior and random statiatical complexity. Therefore, it is necessary to describe the crack evolution with the fractal theory. The pioneering studies [15-17] mainly focus on the connection between fractal dimension and growth process of fatigue crack. Wang et al. [17] proposed a damage model to investigate the collective evolution of short fatigue cracks. However, only plastic strain energy density was considered in the proposed model, which is only applicable for loading with constant amplitude. Obviously, it needs modification under cyclic thermal loading with variable amplitude.

The main objective of this paper is to analyze the microcrack of compacted graphite iron during thermal fatigue of variable amplitude, which is induced by pulsed laser. The initiation and propagation of microcrack is discussed. The box-counting dimension method is applied to estimate the fractal dimension of microcracks under complex thermal conditions. A modified Paris-type prediction model based on fractal theory is proposed based on cyclic energy, including plastic strain energy and elastic strain energy. Thermal fatigue experiments under different levels of strain energy are carried out to verify the model.

\section{Experimental material and procedure}

EN-GJV-450 cast iron material is investigated in this paper, while the chemical composition is listed in Table 1. The original microstructure after etching is showed in Fig. 1. The graphite is mainly in a worm-like form with rounded edges (average length of $100 \mu \mathrm{m})$, and partly in a flaked or spheroidal form. The matrix of compacted graphite iron studied in this paper is pearlite with a variety of lamellar structures, and a small fraction of ferrite. The compacted graphite particles appear worm-shaped when viewed in two dimensions, however, the individual worms are connected to their nearest neighbours within the eutectic cell, which is nearly $300 \mu \mathrm{m}$ and is depicted with yellow dashed line in Fig. 1. The specimens are cut into a cylindrical shape, while the diameter and thickness is $18 \mathrm{~mm}$ and $5 \mathrm{~mm}$, respectively. The sample surface is polished with sandpaper, and cleaned carefully before testing. In addition, the physical and mechanical properties of EN-GJV-450 materiral are listed in Table 2, in order for energy analysis in the finite element simulation.

An experimental system is designed based on Nd:YAG millisecond pulsed laser with wavelength of 1064 nm, which mainly serves as the heat source. The schematic diagram of testing system is presented in Fig. 2(a). Surface temperature in the center of specimen is detected by infrared pyrometer, and serves as the process signal transferred to the control software. The compressed air is supplied to the backside of specimen through a specical designed nozzle, for maintaining the desired temperature gradients across the sample.

In order to simulate the actual working conditions with different thermal cycles, a complete testing cycle is designed to include three parts: the heating stage, the high-cycle stage, and the cooling stage, as shown in Fig. 2(b). The minimum temperature and the maximum temperature are marked as $\mathrm{T}_{\min }$ and $\mathrm{T}_{\max }$, respectively. Therefore, the amplitude of low-cycle stage is the difference

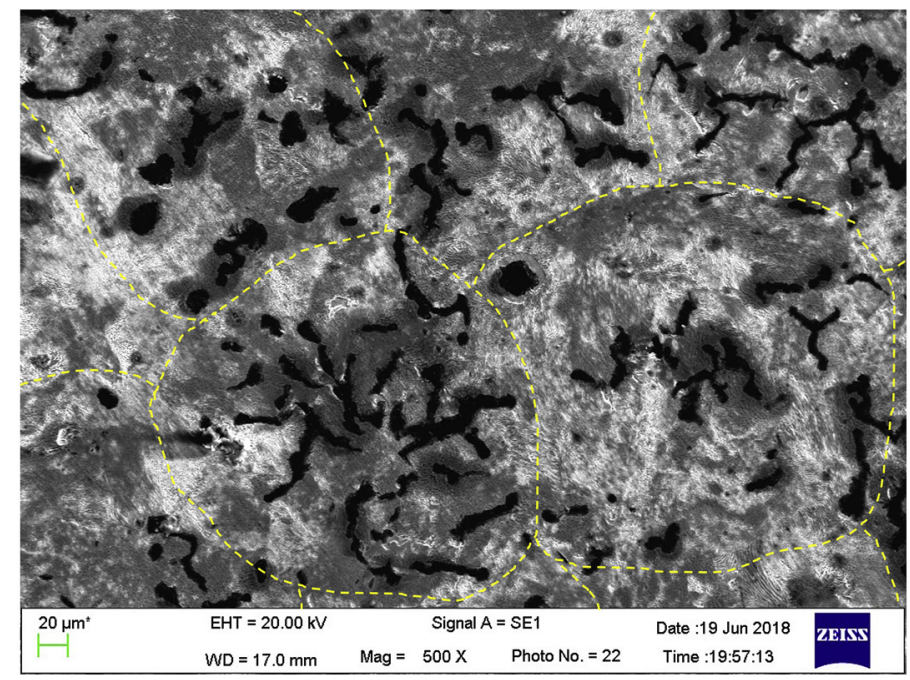

Fig. 1. Typical microstructure of EN-GJV-450 material after etching. 
Table 2

Material parameter of EN-GJV-450 for simulation.

\begin{tabular}{|c|c|c|c|c|c|c|}
\hline $\mathrm{T}$ & $\mathrm{K}$ & $\mathrm{C}$ & $\rho$ & v & $\alpha$ & $\mathrm{E}$ \\
\hline$\left({ }^{\circ} \mathrm{C}\right)$ & $\left(\mathrm{W} \cdot \mathrm{m}^{-1} \cdot \mathrm{K}^{-1}\right)$ & $\left(\mathrm{J} \cdot \mathrm{kg}^{-1} \cdot \mathrm{K}^{-1}\right)$ & $\left(\mathrm{kg} \cdot \mathrm{m}^{-3}\right)$ & & $\left(\mathrm{K}^{-1}\right)$ & (GPa) \\
\hline 20 & 43.0 & 441 & 7090 & 0.241 & / & 106 \\
\hline 100 & 41.9 & 470 & & 0.266 & $9.61 \times 10^{-6}$ & 101 \\
\hline 200 & 40.2 & 513 & & 0.258 & $11.7 \times 10^{-6}$ & 92.3 \\
\hline 300 & 38.6 & 562 & & 0.236 & $12.7 \times 10^{-6}$ & 83.8 \\
\hline 400 & 36.4 & 615 & & 0.224 & $13.3 \times 10^{-6}$ & 77.3 \\
\hline 500 & 33.8 & 674 & & 0.216 & $13.9 \times 10^{-6}$ & 71.2 \\
\hline
\end{tabular}

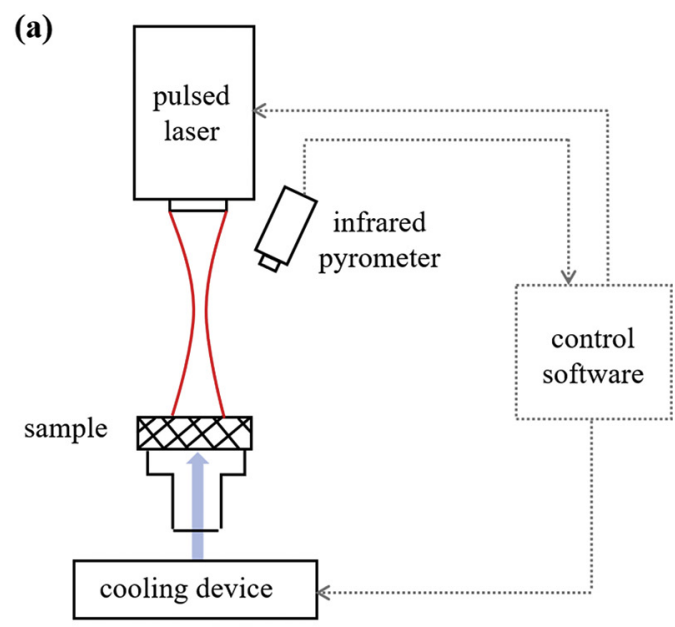

(b)

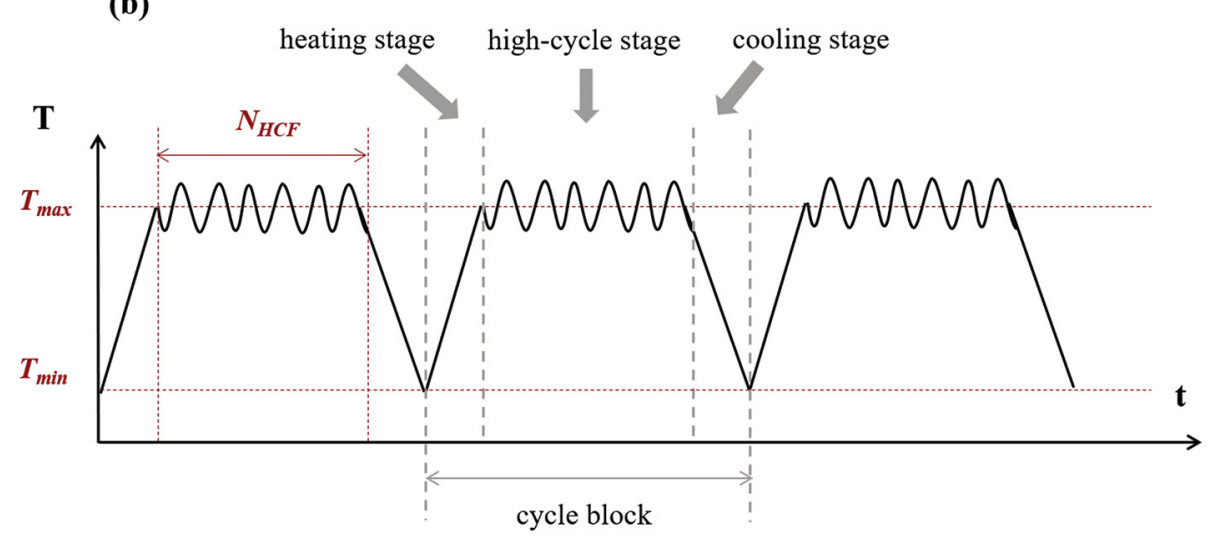

Fig. 2. Schematic diagram of (a) testing system; (b) testing cycle.

between $T_{\max }$ and $\mathrm{T}_{\min }$. The pulse width, repetition rate and single pulse energy are selected to be $8 \mathrm{~ms}, 20 \mathrm{~Hz}$ and $9 \mathrm{~J}$, respectively, and the temperature-controlled mode is chosen at this stage. Once the detected temperature reaches $\mathrm{T}_{\text {max }}$, the laser parameters are changed automatically to another set for small temperature change in the high-cycle stage. The pulse width, repetition rate and single pulse energy in the high-cycle stage are $10 \mathrm{~ms}, 4 \mathrm{~Hz}$ and $15 \mathrm{~J}$, respectively. The temperature amplitude in the low-cycle stage and high-cycle stage is about $400{ }^{\circ} \mathrm{C}$ and $40^{\circ} \mathrm{C}$, respectively. Once the prescribed cycles (marked as $\mathrm{N}_{\mathrm{HCF}}$ ) are completed, the cooling medium is provided automatically, and the cooling stage begins. When the surface temperature drops to $\mathrm{T}_{\mathrm{min}}$, a whole cycle of variable loading is completed.

In this paper, fatigue crack is observed with optical microscope (OM) and scanning electron microscope (SEM), in order to analyze the crack information and calculate the fractal dimension. Firstly, image processing software such as PHOTOSHOP is used to identify the microcrack contour. After that, MATLAB program is applied for binary processing of the extracted profile, and calculation of fractal dimension based on the pixel. 

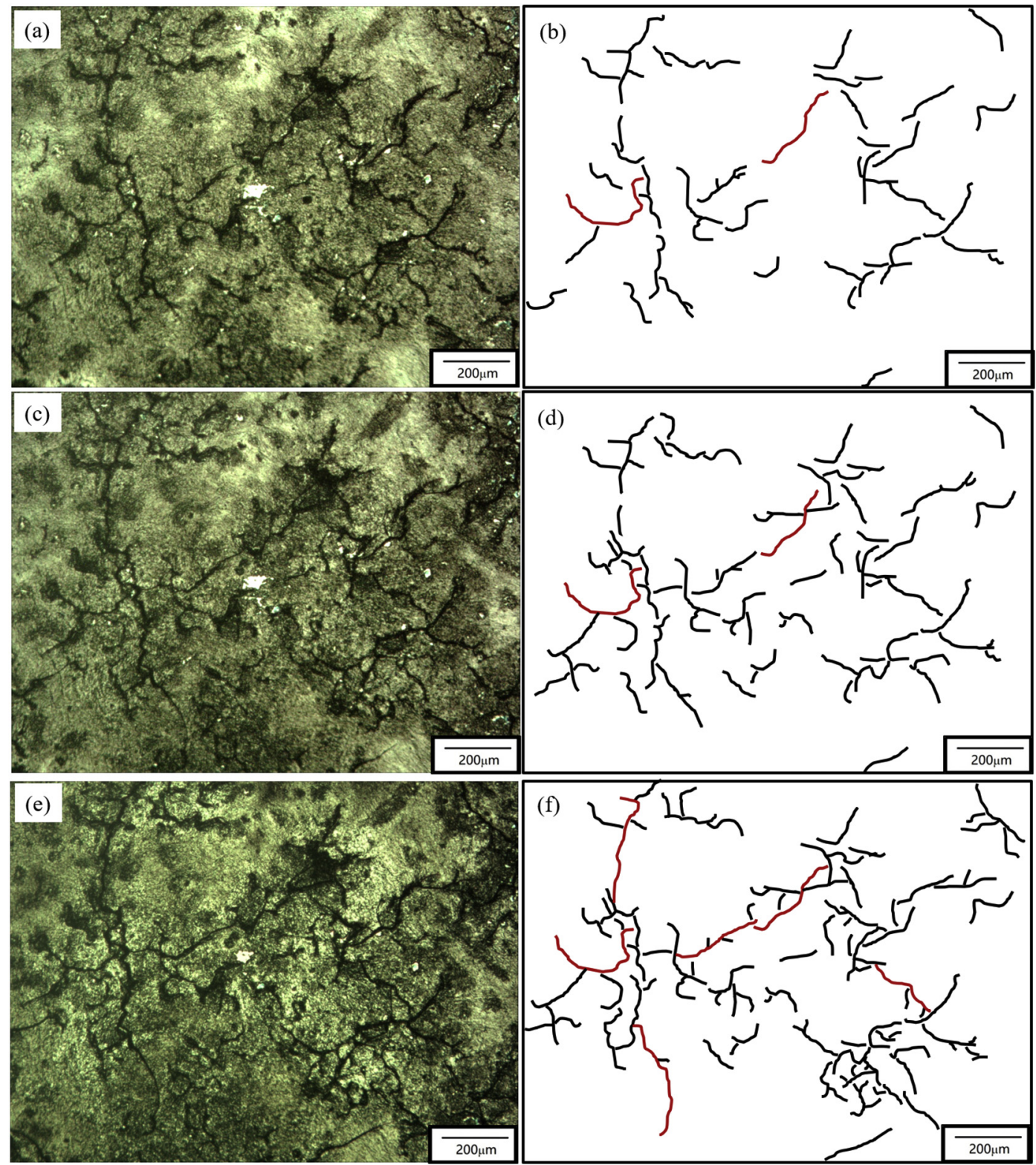

Fig. 3. Surface microcracks and the corresponding extracted profile $\left(\mathrm{T}_{\min }=100^{\circ} \mathrm{C}, \mathrm{T}_{\max }=450{ }^{\circ} \mathrm{C}, \mathrm{N}_{\mathrm{HCF}}=5 \times 10^{3}\right)$. (a) (b) after $1 \mathrm{cycle}$; (c) (d) after 10 cycles; (e) (f) after 40 cycles.

\section{Microstructural analysis of fatigue crack}

The crack evolution is presented in Fig. 3 , and the corresponding testing parameters, such as $\mathrm{T}_{\min }, \mathrm{T}_{\max }, \mathrm{N}_{\mathrm{HCF}}$, are $100{ }^{\circ} \mathrm{C}, 450{ }^{\circ} \mathrm{C}$ and $5 \times 10^{3}$, respectively. As shown in Fig. 3(a), (c), (e), the sample surface is severely oxidized due to long time exposure to high temperature environment containing oxygen. In order for quantitative analysis, the image processing software is applied to extract the profile of surface microcrack, as shown in Fig. 3(b), (d), (f). Under the thermal loading provided by pulsed laser, although the equivalent stress is below the yield limit of cast iron, the slip band will occur in the local surface, especially within the laser spot, which is attributed to the inevitable inhomogeneity of the structure or properties. As the sample surface is under plane stress state, it is easy for plastic slip [18]. Repeated cyclic slip strain forms the initiation core of microcracks. After the first cycle, as in Fig. 3(a), (b), the microcrack initiation has begun, indicating that, it is easy for cast iron material to cause microcrack initiation under cyclic thermal loading with variable amplitude. Accumulated thermal damage mainly includes plastic deformation produced by thermal loading of large amplitude, and elastic deformation caused by thermal loading of small amplitude. Once the microcrack initiates in a certain location, the stored strain energy will be transferred to the surface energy for a new crack. Therefore, it is difficult for other new microcrack to initiate around this position. After 10 cycles (as shown in Fig. 3(c), (d)), as the test going, the cracks propagate 

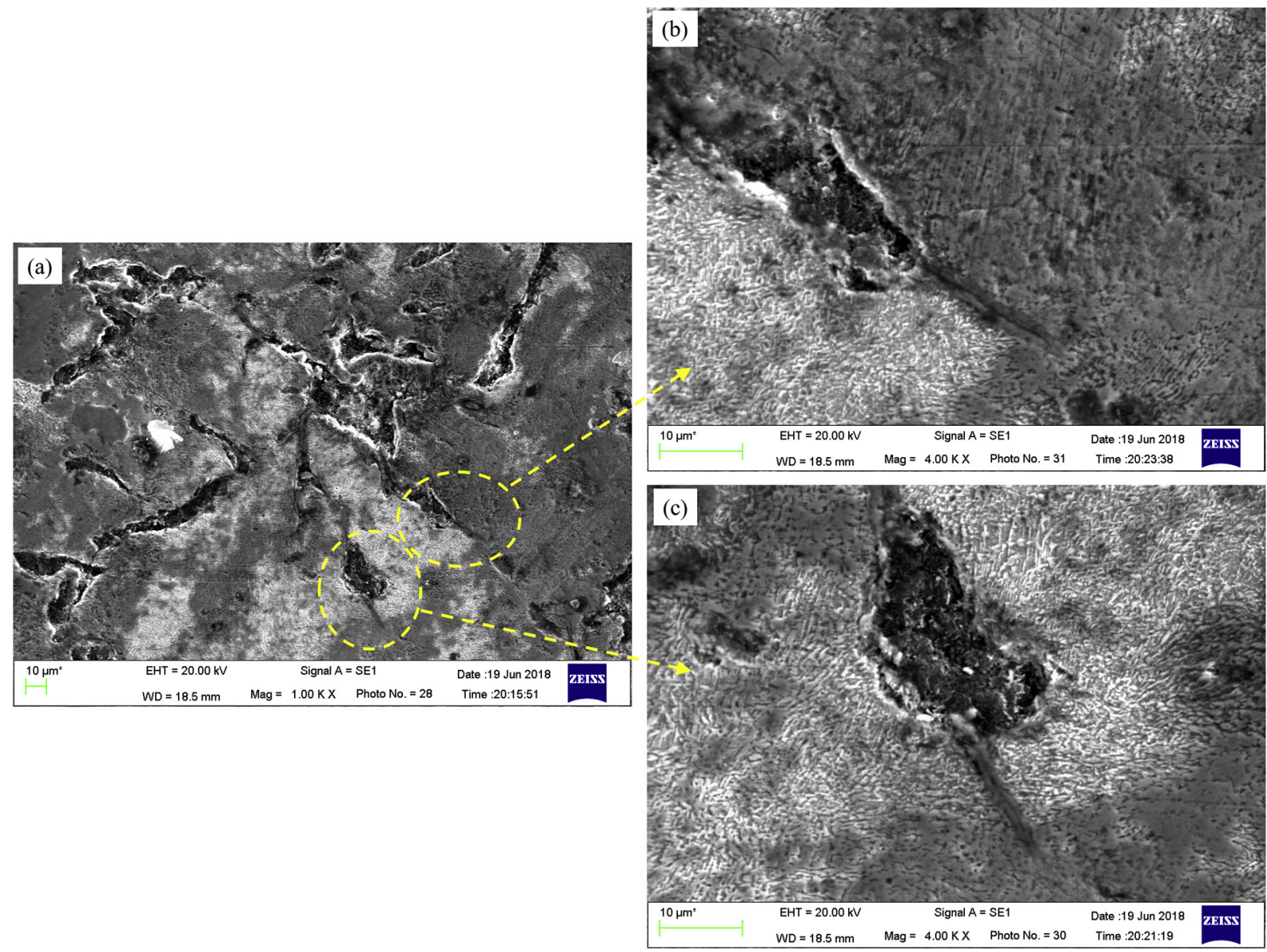

Fig. 4. Microcracks initiated from the graphite phase after 40 cycles. $\left(\mathrm{T}_{\min }=100^{\circ} \mathrm{C}, \mathrm{T}_{\max }=450^{\circ} \mathrm{C}, \mathrm{N}_{\mathrm{HCF}}=5 \times 10^{3}\right)$.

along the graphite phases both on the surface and in the thickness direction, resulting in the increase of crack length and crack number. Under the repeated loading of tensile stresses and compressive stresses generated in the thermal cycle, the graphite phases strip from interface gradually. After 40 cycles (as shown in Fig. 3(e), (f)), more and more short cracks appear. At the same time, several microcracks grow up and coalesce together to connect adjacent graphite phases, forming long cracks.

It can be seen from Fig. 3, the crack length is different. The number of microcrack shorter than $0.1 \mathrm{~mm}$ is the most, while the number of microcrack longer than $0.3 \mathrm{~mm}$ is the least. As stated in Part II, the average length of graphite phase and eutectic cluster is $0.1 \mathrm{~mm}$ and $0.3 \mathrm{~mm}$, respectively. Therefore, the crack shorter than $0.1 \mathrm{~mm}$ is defined as "secondary microcrack", which is equivalent to the size of graphite phase. The crack longer than $0.3 \mathrm{~mm}$ is defined as "main microcrack", which is larger than the size of eutectic cluster. In addition, the main microcracks are depicted with red lines in Fig. 3. The difference of these two kinds of cracks is not only the length, but also the behavior of initiation and propagation, which can be proved by the following microstructural observation.

The microstructure of compacted graphite iron mainly includes two parts, the graphite phase and the iron matrix. The properties of graphite phase and iron matrix are of great difference, such as the thermal expansion coefficient, thermal conductivity, tensile strength and so on. Therefore, under cyclic thermal loading of variable amplitude, the graphite phase tends to separate from the matrix, and the microcrack tends to initiate from graphite phase. As presented in Fig. 1, there are two kinds of morphologies for graphite phase, such as vermicular and spheroidal. In general, the initiated crack around is different, which can be observed in Fig. 4. For long vermicular graphite $(\sim 100 \mu \mathrm{m})$, the stress concentration around the graphite tip is relatively large, so cracks usually initiate at the graphite tip and propagate along the length direction. Especially when the vermicular graphite locates at the eutectic boundary, as in Fig. 4(b), the initiated secondary microcrack will propagate along the interface. As for spheroidal graphite, the crack initiation and propagation show great randomness, and always occur in the direction of maximal tensile stress. As shown in Fig. 4(c), the secondary microcrack initiates from the interface between the spheroidal graphite and the iron matrix, and propagates within a eutectic cell.

However, the situation for short vermicular graphite $(\sim 20 \mu \mathrm{m})$, is between the two kinds above. It can be seen from Fig. 5 , since the characteristic length of short vermicular graphite is of the same level with the spheroidal graphite, the propagation behaves like the spheroidal graphite to same extent. The propagated direction of secondary microcrack initiated from short vermicular graphite, is not strictly along the length direction, however, shows randomness near the graphite tip, as demonstrated in Fig. 5(b). In addition, 

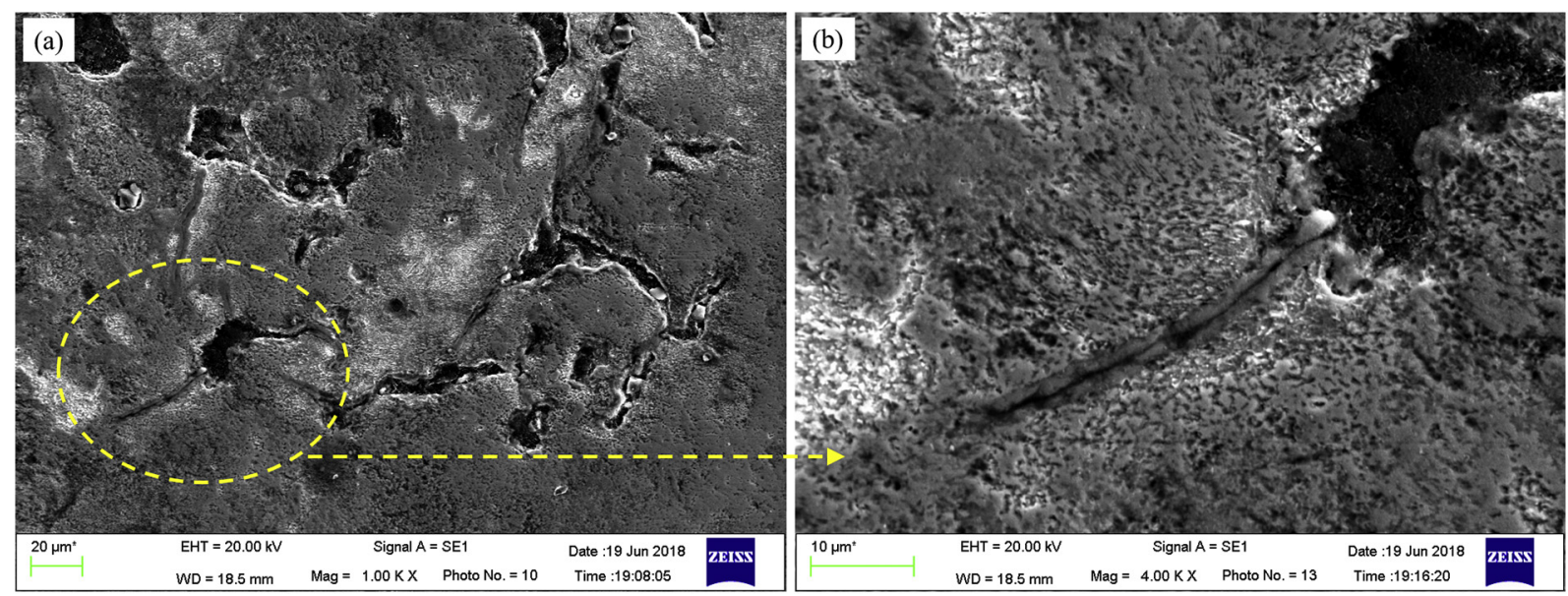

Fig. 5. Secondary microcrack initiated from the graphite phase after 40 cycles. $\left(\mathrm{T}_{\min }=100^{\circ} \mathrm{C}, \mathrm{T}_{\max }=450^{\circ} \mathrm{C}, \mathrm{N}_{\mathrm{HCF}}=5 \times 10^{3}\right)$.

the secondary microcrack usually propagates within a eutectic cell. The crack pattern induced by thermal loading with variable amplitude is different from that caused by thermal loading with constant amplitude [11]. Due to the relatively small temperature change in the high-cycle stage, more secondary microcracks occur. Once the secondary microcrack initiates, the laser energy absorbed on the surface will transfer into the energy for forming new crack surface. Since the energy provided in the high-cycle stage is not enough to break across the eutectic boundary, therefore, the propagation of secondary microcrack usually limits in a eutectic cell.

As defined above, the length of main microcrack is larger than the size of eutectic cluster. The main microcrack is mainly caused by large temperature change in the low-cycle stage, which supplies enough energy to propagate across the eutectic boundary. However, once the tip of main microcrack is perpendicular to the eutectic boundary (marked as the red dashed line in Fig. 6(c)), especially when there is another microcrack in front, the propagation of main microcrack will stop. As shown in Fig. 6(b), in the middle of main microcrack, one secondary microcrack initiates around the severe oxidation zone and grows within a eutectic cell, showing bifurcation phenomenon. When there is spheroidal graphite in front of the crack tip, as in Fig. 6(d), the secondary microcrack tends to bypass the spheroidal graphite. In contrast, the propagation of main microcrack will continue until connecting the spheroidal graphite, as demonstrated in Fig. 6(e).
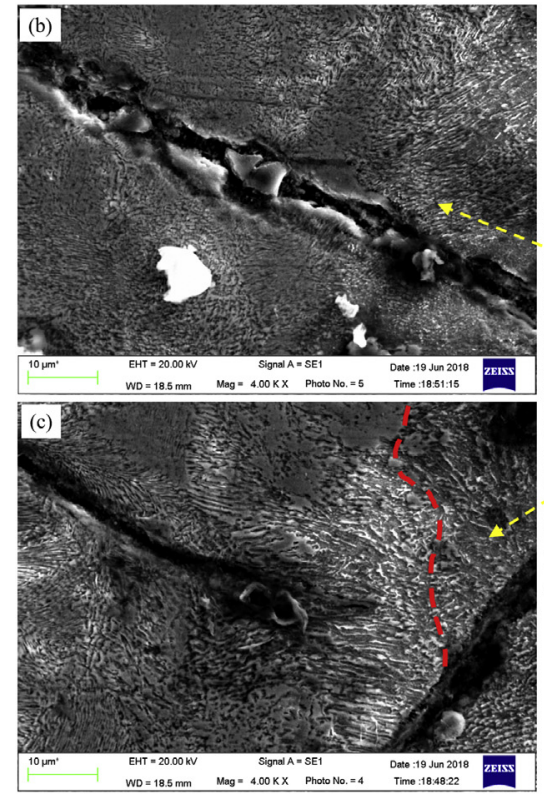
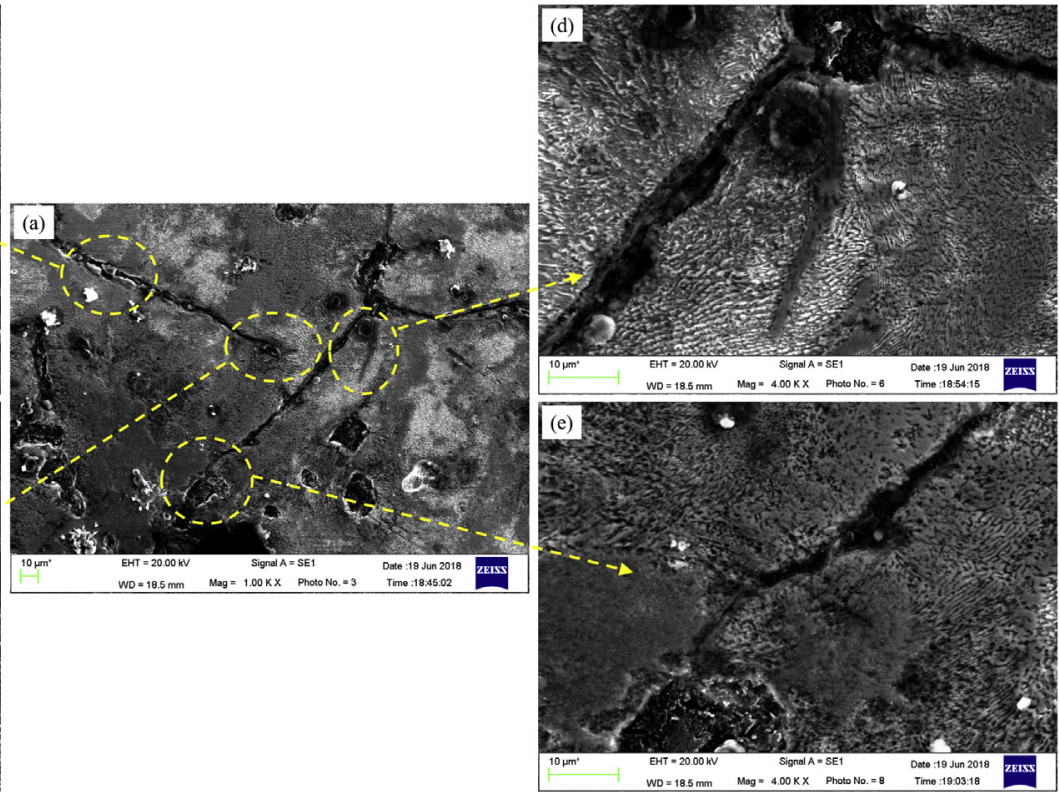

Fig. 6. Surface microcracks after 40 cycles $\left(\mathrm{T}_{\min }=100^{\circ} \mathrm{C}, \mathrm{T}_{\max }=450^{\circ} \mathrm{C}, \mathrm{N}_{\mathrm{HCF}}=5 \times 10^{3}\right)$. 

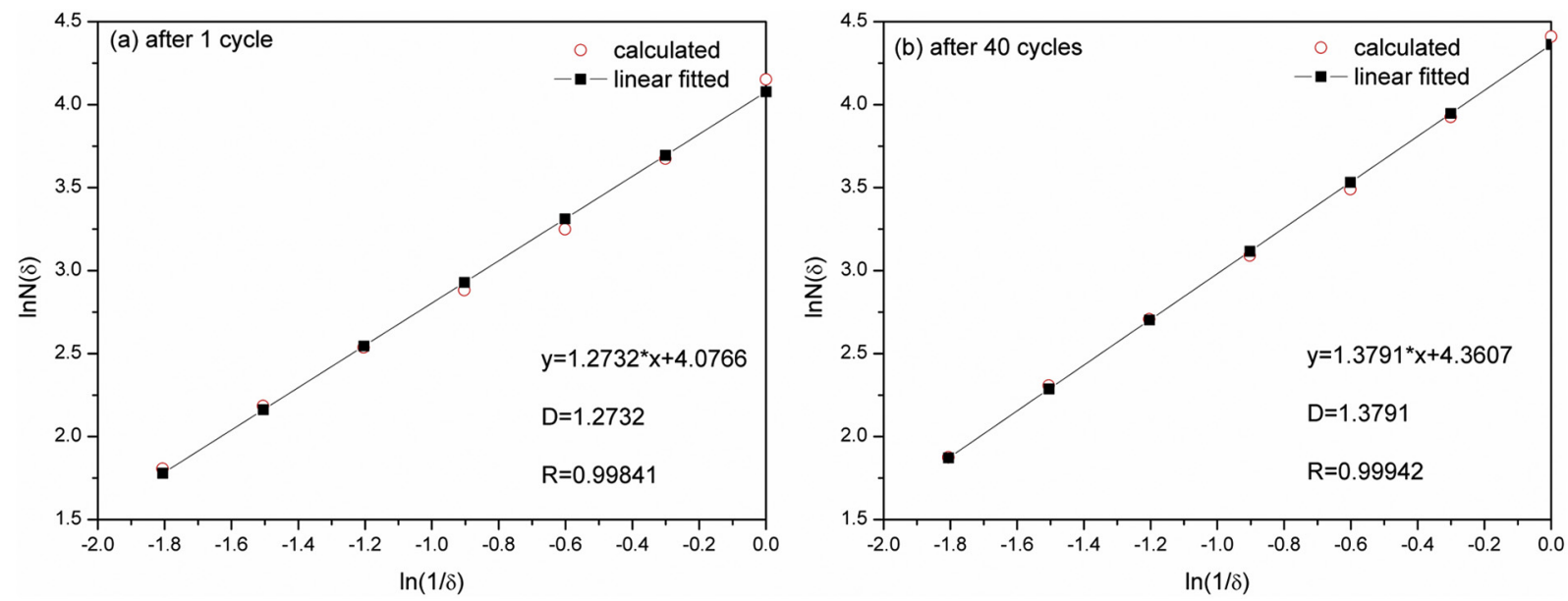

Fig. 7. Fractal dimension calculation of surface microcracks $\left(\mathrm{T}_{\min }=100^{\circ} \mathrm{C}, \mathrm{T}_{\max }=450^{\circ} \mathrm{C}, \mathrm{N}_{\mathrm{HCF}}=5 \times 10^{3}\right.$ ). (a) after 1 cycle; (b) after 40 cycles.

\section{Evolution prediction}

\subsection{Fractal analysis}

It can be found from the above analysis that, in the case of multiple microcrack propagation, it is not appropriate to use da/dN for evaluating the crack evolution, because the crack length is hard to measure. The surface microcracks show strong collective behavior during the whole growth process [19]. In addition, former research show that, the cracked solid can be regarded as nonlinear dissipative system [20,21], showing good statistical self-similarity. Therefore, fractal dimension (marked as D) in the fractal theory can be applied to describe and characterize the microcrack evolution quantitatively [22-24]. The calculation of D is based on the extracted crack image and the method of box-counting dimension [17]. In the box-counting dimension method, a linear regression equation is used to estimate the fractal dimension:

$$
\log N(r)=D \log (r)+\log C_{s}
$$

where $\mathrm{N}(\mathrm{r})$ is the number of square boxes needed to recover the cracks in the image, $\mathrm{D}$ is the fractal dimension, $\mathrm{r}$ is the side length of square box, and $\mathrm{C}_{\mathrm{s}}$ is a constant.

A series of $\log \mathrm{N}(\mathrm{r})$ against $\log (\mathrm{r})$ data are calculated and plotted in double-logarithmic coordinates, and the corresponding linear regression lines are shown in Fig. 7. The correlation coefficients in Fig. 7 are larger than 0.99, revealing that the crack images have fractal characteristics.

It can be inferred from Fig. 7 that, the fractal dimension is a function of time, reflecting the process of thermal fatigue damage. Therefore, the growth rate of fractal dimension (marked as $\mathrm{dD} / \mathrm{dN}$ ) can be regarded as a parameter which represents the damage degree of specimens. It is worth noting that, the thermal damage of specimens varies with the change of cyclic thermal loading. As a result, different experimental parameters, such as $\mathrm{T}_{\min }, \mathrm{T}_{\max }$ and $\mathrm{N}_{\mathrm{HCF}}$, are selected in order to calculate $\mathrm{dD} / \mathrm{dN}$ under different testing conditions, which are listed in Table 3 . It can be seen that, for the same $\mathrm{T}_{\min }$ and $\mathrm{N}_{\mathrm{HCF}}, \mathrm{dD} / \mathrm{dN}$ increases with the increase of $\mathrm{T}_{\text {max }}$. Similarly, for the same $\mathrm{T}_{\min }$ and $\mathrm{T}_{\max }, \mathrm{dD} / \mathrm{dN}$ increases with the increase of $\mathrm{N}_{\mathrm{HCF}}$. Higher $\mathrm{T}_{\max }$ and larger $\mathrm{N}_{\mathrm{HCF}}$ mean more laser energy is input through pulsed laser, and more serious thermal damage can be expected. There must be certain connection between fractal dimension and input energy, which is the basic of the following prediction model.

\subsection{Prediction model for fatigue crack}

The proposed model in this paper is based on Sandor's proposal [25], however, modification is needed. Under cyclic thermal

Table 3

Growth rate of fractal dimension for different testing conditions after 40 cycles.

\begin{tabular}{lllll}
\hline Condition & $\left.\mathrm{T}_{\min }{ }^{\circ} \mathrm{C}\right)$ & $\left.\mathrm{T}_{\max }{ }^{\circ} \mathrm{C}\right)$ & $\mathrm{N}_{\mathrm{HCF}}$ & $\mathrm{dD} / \mathrm{dN}$ \\
\hline 1 & 100 & 350 & $10^{3}$ & $4.04 \times 10^{-3}$ \\
2 & 100 & 400 & $10^{3}$ & $5.59 \times 10^{-3}$ \\
3 & 100 & 450 & $10^{3}$ & $6.28 \times 10^{-3}$ \\
4 & 100 & 500 & $10^{3}$ & $7.42 \times 10^{-3}$ \\
5 & 100 & 450 & $5 \times 10^{2}$ & $2.41 \times 10^{-3}$ \\
6 & 100 & 450 & $5 \times 10^{3}$ & $6.51 \times 10^{-3}$ \\
7 & 100 & 450 & $10^{4}$ & $7.47 \times 10^{-3}$ \\
\hline
\end{tabular}


Table 4

Strain energy density for different testing conditions.

\begin{tabular}{llll}
\hline Condition & $\Delta \mathrm{W}_{\mathrm{pl}}\left(\mathrm{N} \cdot \mathrm{m}^{-2}\right)$ & $\Delta \mathrm{W}_{\mathrm{el}}\left(\mathrm{N} \cdot \mathrm{m}^{-2}\right)$ & $\Delta \mathrm{W}_{\mathrm{th}}\left(\mathrm{N} \cdot \mathrm{m}^{-2}\right)$ \\
\hline 1 & 32,170 & 89,888 & 72,000 \\
2 & 57,644 & & \\
3 & 102,142 & & \\
4 & 248,461 & & \\
5 & 102,142 & & \\
6 & 102,142 & & \\
7 & 102,142 & & \\
\hline
\end{tabular}

loading with variable amplitude, the mechanism of crack initiation is tensile-stress induced cracking in the cooling stage, and peak compressive-stress induced cracking during the high-cycle stage [26]. During the low-cycle stage, the significant temperature change produces large thermal loading, and the corresponding input energy is large enough to induce plastic deformation. As a result, thermal fatigue crack will initiate within the local area of large plastic strain energy.

In contrast, the temperature change in the high-cycle stage is relatively small, and the induced transient elastic stress is smaller than the yield limit of material. At the crack tip induced in the low-cycle stage, additional elastic strain is superimposed and wedging effect occurs. The crack tip opening displacement increases, and additional driving force for crack propagation is provided. Therefore, both plastic strain energy in the low-cycle stage and elastic strain energy in the high-cycle stage, should be considered in the prediction model.

The strain energy density can be estimated by finite element simulation, and the simulated model was proposed in [11]. In this paper, von Mises yield criterion, isotropic linear hardening model, and Prandtl-Reuss incremental theory of plastic flow, are applied for strain energy simulation during the thermal fatigue process induced by pulsed laser. The simulated results under different testing conditions are listed in Table 4 , where $\Delta \mathrm{W}_{\mathrm{pl}}$ is the plastic strain energy density in the low-cycle stage, $\Delta \mathrm{W}_{\mathrm{el}}$ is the elastic strain energy density in the high-cycle stage.

Based on the relationship between $\mathrm{dD} / \mathrm{dN}$ and cyclic strain energy density, a modified Paris-type model for the evolution of $\mathrm{D}$ is proposed as following:

$$
\frac{d D}{d N}=C_{1}\left(\Delta W_{p l}\right)^{m}+\int_{0}^{N_{H C F}} C_{2}\left(\Delta W_{e l}-\Delta W_{t h}\right)^{m} d N_{H C F}
$$

where $\mathrm{C}_{1}, \mathrm{C}_{2}, \mathrm{~m}$ are material constants, $\mathrm{N}_{\mathrm{HCF}}$ is the superimposed number of high-cycle loading in every cycle, and $\Delta \mathrm{W}_{\text {th }}$ is the threshold of elastic strain energy density. Assuming that, the elastic strain energy density produced by each high-cycle loading is the same, therefore, Eq. (2) can be simplified as

$$
\frac{d D}{d N}=C_{1}\left(\Delta W_{p l}\right)^{m}+C_{2}\left(\Delta W_{e l}-\Delta W_{t h}\right)^{m} N_{H C F}
$$

$\mathrm{dD} / \mathrm{dN}$ can be calculated from experimental results, and the strain energy density $\Delta \mathrm{W}_{\mathrm{pl}}$ and $\Delta \mathrm{W}_{\mathrm{el}}$ can be simulated by finite element method. In addition, $\Delta \mathrm{W}_{\text {th }}$ is a material constant to some extent, which can be inferred from the threshold value of high-cycle strain under the mechanical loading with variable amplitude. For the EN-GJV-450 material, high-cycle mechanical strain was superimposed during the process of thermomechanical fatigue in [27]. Experimental results showed that, when $\mathrm{T}_{\max }$ is $450{ }^{\circ} \mathrm{C}$, the lifetime is significantly affected when the superimposed strain amplitude of high-cycle loading is $0.05 \%$. Therefore, according to the elastic modulus of EN-GJV-450 material, the corresponding threshold of elastic strain energy density can be calculated as listed in Table 4.

ORIGIN software is applied for parameter fitting, and the results are listed in Table 5. The experimental samples is split into two groups. The experimental samples of Condition 1, 3, 5 and 7 are used for calibration, and the experimental samples of Condition 2, 4, and 6 are used for validation. The sample number of each condition is five, and the experimental results of $\mathrm{dD} / \mathrm{dN}$ in Table 3 is the average of five samples. The material constants $\mathrm{C}_{1}, \mathrm{C}_{2}$ and $\mathrm{m}$ is fit and validated by the experimental results. The experimental results of $\mathrm{dD} / \mathrm{dN}$ and FEM analysis of cyclic strain energy density are in good agreement with the proposed model. Such match also demonstrates that the model is valid for estimating thermal fatigue damage of variable amplitude with acceptable accuracy.

Table 5

Fitting result of the parameters.

\begin{tabular}{lll}
\hline Parameter & Fitting value & $\mathrm{R}^{2}$ \\
\hline $\mathrm{C}_{1}$ & $1.61 \times 10^{-4}$ & 0.997 \\
$\mathrm{C}_{2}$ & $1.44 \times 10^{-8}$ & 0.938 \\
$\mathrm{~m}$ & 0.298 & 0.998 \\
\hline
\end{tabular}




\section{Conclusion}

In this paper, thermal fatigue crack of compacted graphite iron under variable amplitude is studied. According to the microstructural observation of surface microcracks, the characteristics of initiation and propagation process under cyclic thermal loading with variable amplitude is analyzed. In addition, evolution model is proposed to evaluate thermal damage. The main conclusions are listed as following:

(1) The secondary microcrack (shorter than $0.1 \mathrm{~mm}$ ) caused by the superimposed high-cycle thermal loading shows different behavior of initiation and propagation with the main microcrack (longer than $0.3 \mathrm{~mm}$ ). The propagation of secondary microcrack usually limits in a eutectic cell, because that the energy provided in the high-cycle stage is not enough to break across the eutectic boundary. However, the main microcrack is mainly caused by large temperature change in the low-cycle stage, which supplies enough energy to propagate across overcome the eutectic boundary.

(2) A modified Paris-type model is proposed based on fractal theory, which both plastic strain energy density and elastic strain energy density are taken into consideration. The threshold of elastic strain energy density $\Delta \mathrm{W}_{\text {th }}$ is introduced to estimate the contribution of elastic strain energy density to damage evolution. The proposed model of crack evolution characterizes the relationship between damage parameters (fractal dimension) and external loading (cyclic strain energy), which is helpful for lifetime prediction of components and materials working under thermal fatigue with variable amplitude.

\section{Acknowledgments}

The experimental work was supported by Professor Gang Yu in Institute of Mechanics, Chinese Academy of Sciences. This research was supported by the Doctor's Scientific Research Foundation of Hezhou University (NO. HZUBS201806). This research was also supported by the Hezhou Foundation Research and Development of Science and Technology (NO. 201707007 \& NO. 201808011). In addition, this research was supported by the Teaching Reform Project for Higher Education Undergraduate Course of Guangxi Education Department (NO.2015JGA360).

\section{References}

[1] M. Górny, M. Holtzer, R. Dańko, Microstructure and Properties of Ductile Iron and Compacted Graphite Iron Castings: The Effects of Mold Sand/Metal Interface Phenomena, Springer, Berlin, 2015

[2] M. Zhang, J. Pang, Y. Qiu, et al., Thermo-mechanical fatigue property and life prediction of vermicular graphite iron, Mater. Sci. Eng. A 698 (2017) 63-72.

[3] T. Seifert, H. Riedel, Mechanism-based thermomechanical fatigue life prediction of cast iron. Part I: models, Int. J. Fatigue 32 (8) (2010) $1358-1367$.

[4] Q. Zhang, Z. Zuo, J. Liu, Failure analysis of a diesel engine cylinder head based on finite element method, Eng. Fail. Anal. 34 (2013) 51-58.

[5] B. Fedelich, H.-J. Kühn, B. Rehmer, B. Skrotzki, Experimental and analytical investigation of the TMF-HCF lifetime behavior of two cast iron alloys, Int. J. Fatigue 99 (2017) 266-278.

[6] L. Weng, S. Lee, On thermal shock resistance of austenitic cast irons, Metal. Transac. A Phys. Metal. Mater. Sci. 22 (8) (1991) $1821-1831$.

[7] Y. Pan, C. An, C. Chang, Effects of graphite shape on thermal fatigue property of thin wall graphitic cast irons, 9th International Symposium on Science and Processing of Cast Iron Luxor, Egypt, 2011, pp. 398-403.

[8] G. Regheere, M. Collignon, A.L. Cristol, et al., Thermocracks ${ }^{\circledR}$, a specific testing machine for evaluation of the thermal fatigue resistance of materials, Proc. Eng. 66 (2013) 250-263.

[9] X. Wang, W. Zhang, B. Guo, et al., The characteristics of microcrack initiation process in cast iron materials under thermal shock test, Mater. Sci. Eng. A 609 (2014) 310-317.

[10] S. Pan, G. Yu, S. Li, et al., Application of millisecond pulsed laser for thermal fatigue property evaluation, Opt. Laser Technol. 99 (2018) 382-391.

[11] S. Pan, G. Yu, S. Li, et al., Experimental and numerical study of crack damage under variable amplitude thermal fatigue for compacted graphite iron EN-GJV-450, Int. J. Fatigue 113 (2018) 184-192.

[12] Z. Gan, G. Yu, S. Li, et al., A novel intelligent adaptive control of laser-based ground thermal test, Chin. J. Aeronaut. 29 (4) (2016) 1018-1026.

[13] Y. Hong, Y. Qiao, An analysis of collective damage for short fatigue cracks based on equilibrium of crack numerical density, Eng. Fract. Mech. 59 (2) (1998) $151-163$.

[14] L. Zheng, Y. Hong, Y. Qiao, Simulations and experiments of stochastic characteristics for collective short fatigue cracks in steels, Fatig. Fract. Eng. Mater. Struct. 25 (2002) 459-466.

[15] P. Stoppel, M. Rybaczuk, The fractal growth of fatigue defects in materials, Int. J. Fract. 103 (2000) 71-94.

[16] R. Ritchie, Incomplete self-similarity and fatigue-crack growth, Int. J. Fract. 132 (2005) 197-203.

[17] L. Wang, Z. Wang, W. Xie, et al., Fractal study on collective evolution of short fatigue cracks under complex stress conditions, Int. J. Fatigue 45 (2012) 1-7.

[18] T. Anderson, Fracture Mechanics-Findamentals and Applications, Third edition, Taylor\&Francis, Boca Raton, 2005.

[19] S. Pan, G. Yu, X. He, et al., Collective evolution of surface microcrack for compacted graphite iron under thermal fatigue with variable amplitude, Int. J. Fatigue 118 (2019) 139-149.

[20] K. Sun, Y. Zhao, Y. Zhang, Fractal dimension of time series applied to identification of critical speed of jeffcott rotor system, Chin. J. Mech. Eng. 18 (3) (2005) 446-448.

[21] I. Konovalenko, P. Maruschak, R. Bishchak, Effect of thermal fatigue cracks on brittle-ductile deformation and failure of cbcm roller surface layers, Metallurgist $56(1-2)(2012) 30-36$.

[22] J. Zhang, H. Su, B. Tang, et al., Fractal characteristic of laser zone remelted Al2O3/YAG eutectic in situ composite, J. Cryst. Growth 310 (2) (2008) 490-494.

[23] P. Mallick, D. Agarwal, C. Rath, et al., Evolution of microstructure and crack pattern in NiO thin films under $200 \mathrm{MeV}$ Au ion irradiation, Radiat. Phys. Chem. 81 (6) (2012) 647-651.

[24] G. Zheng, J. Zhao, L. Li, et al., A fractal analysis of the crack extension paths in a Si3N4 ceramic tool composite, Int. J. Refract. Met. Hard Mater. 51 (2015) $160-168$.

[25] B. Sandor, Fundamentals of Cyclic Stress and Strain, Science Press, Beijing, China, 1985.

[26] R. Miller, D. Zhu, Investigation of thermal high cycle and low cycle fatigue mechanisms of thick thermal barrier coatings, Mater. Sci. Eng. A 245 (1998) $212-223$.

[27] M. Metzger, B. Nieweg, C. Schweizer, et al., Lifetime prediction of cast iron materials under combined thermomechanical fatigue and high cycle fatigue loading using a mechanism-based model, Int. J. Fatigue 53 (2013) 58-66. 